\title{
On the Temperature Dependence of the Rate Constant of the Bimolecular Reaction of two Hydrated Electrons
}

\author{
S.L. Butarbutar ${ }^{1,2}$, Y. Muroya ${ }^{3}$, L. Mirsaleh Kohan $^{1}$, S. Sanguanmith ${ }^{1}$, \\ J. Meesungnoen ${ }^{1}$ and J.-P. Jay-Gerin ${ }^{1^{\star}}$ \\ ${ }^{1}$ Département de Médecine Nucléaire et de Radiobiologie, Faculté de médecine et des sciences de la santé, \\ Université de Sherbrooke, 3001, $12^{e}$ Avenue Nord, Sherbrooke (Québec) J1H 5N4, Canada \\ ${ }^{2}$ Center for Reactor Technology and Nuclear Safety, National Nuclear Energy Agency, \\ Puspiptek Area, Serpong, Tangerang 15314, Indonesia \\ ${ }^{3}$ Institute of Scientific and Industrial Research (ISIR), Osaka University, Mihogaoka 8-1, \\ Ibaraki, Osaka 567-0047, Japan
}

\section{ARTICLE INFO}

Article history:

Received 13 June 2013

Received in revised form 27 August 2013

Accepted 28 August 2013

Keywords:

Water radiolysis

High temperature

Self-reaction of the hydrated electron

Rate constant

Yield of $\mathrm{H}_{2}$

Linear energy transfer (LET)

Monte Carlo track chemistry calculations

\begin{abstract}
A B S T R A C T
It has been a longstanding issue in the radiation chemistry of water that, even though $\mathrm{H}_{2}$ is a molecular product, its "escape" yield $g\left(\mathrm{H}_{2}\right)$ increases with increasing temperature. A main source of $\mathrm{H}_{2}$ is the bimolecular reaction of two hydrated electrons $\left(\mathrm{e}_{\mathrm{aq}}^{-}\right)$. The temperature dependence of the rate constant of this reaction $\left(k_{1}\right)$, measured under alkaline conditions, reveals that the rate constant drops abruptly above $\sim 150^{\circ} \mathrm{C}$. Recently, it has been suggested that this temperature dependence should be regarded as being independent of $\mathrm{pH}$ and used in hightemperature modeling of near-neutral water radiolysis. However, when this drop in the $\mathrm{e}^{-}$aq self-reaction rate constant is included in low (isolated spurs) and high (cylindrical tracks) linear energy transfer (LET) modeling calculations, $g\left(\mathrm{H}_{2}\right)$ shows a marked downward discontinuity at $\sim 150^{\circ} \mathrm{C}$ which is not observed experimentally. The consequences of the presence of this discontinuity in $g\left(\mathrm{H}_{2}\right)$ for both low and high LET radiation are briefly discussed in this communication. It is concluded that the applicability of the sudden drop in $k_{1}$ observed at $\sim 150^{\circ} \mathrm{C}$ in alkaline water to near-neutral water is questionable and that further measurements of the rate constant in pure water are highly desirable.
\end{abstract}

(C) 2013 Atom Indonesia. All rights reserved

\section{INTRODUCTION}

In nuclear power plants (NPPs), water is used as both a coolant and neutron moderator. Over the operating temperature range of $275-325^{\circ} \mathrm{C}$, water is irradiated heavily in the reactor core by some mixture of fast electrons and recoil ions of hydrogen and oxygen, which have characteristically different linear energy transfer (LET) values (in the range from $\sim 0.3$ to $40-60 \mathrm{keV} / \mu \mathrm{m}$, respectively). This irradiation results in the chemical decomposition (radiolysis) of water and leads to the formation of the short-lived reactive radicals $\mathrm{e}^{-}$aq (hydrated electron), $\mathrm{H}^{\cdot},{ }^{\circ} \mathrm{OH}$, and $\mathrm{HO}_{2}{ }^{\circ}$ (or $\mathrm{O}_{2}{ }^{-}$, depending on $\mathrm{pH}$ ) and the longerlived molecular products $\mathrm{H}_{2}$ and $\mathrm{H}_{2} \mathrm{O}_{2}$ (and eventually $\mathrm{O}_{2}$ ). These species can promote corrosion, cracking, and hydrogen pickup both in

\footnotetext{
* Corresponding author.

E-mail address: jean-paul.jay-gerin@USherbrooke.ca
}

the core and in the associated piping components of the reactor [1-5].

Theoretical calculations and chemical models of the radiation chemistry of water in the reactor core require the radiolytic yields (defined as the number of species formed or destroyed per $100 \mathrm{eV}$ of energy absorbed [6,7]) of the primary species for both fast neutrons and $\gamma$-radiation. The rate constants for all of the reactions involving these species are also required. The yields and chemical kinetic data for high-temperature light water radiolysis, up to $350^{\circ} \mathrm{C}$, have recently been compiled and reviewed by Elliot and Bartels [8].

For water at neutral or near-neutral $\mathrm{pH}$ under low-LET radiation (such as ${ }^{60} \mathrm{Co} \gamma$-rays and fast electrons), the primary (or "escape") yields (commonly denoted $g$-values) of the free radicals $\mathrm{e}^{-}{ }_{\text {aq }}, \mathrm{H}^{\bullet}$, and ${ }^{\circ} \mathrm{OH}$ continuously increase when the temperature is increased, while the primary yield of $\mathrm{H}_{2} \mathrm{O}_{2}$ decreases [8,9]. Although $\mathrm{H}_{2}$ is a molecular product, $g\left(\mathrm{H}_{2}\right)$ increases monotonically with 
temperature, particularly above $200^{\circ} \mathrm{C}$ [8-13]. $\mathrm{H}_{2}$, whose formation is favored by fast neutron (highLET recoil-ion) radiolysis [4], is an important component associated with the corrosion environment of the coolant system in NPPs. Knowledge of the production of $\mathrm{H}_{2}$ from irradiated water and the amount of "excess" $\mathrm{H}_{2}$ to be added to the primary coolant to mitigate water decomposition and $\mathrm{O}_{2}$ production is crucial to develop better reactor chemistry control and to optimize plant performance [14-16].

\section{THEORY}

In the $\gamma$-radiolysis of water, there are several different mechanisms for the production of molecular hydrogen. Recent studies have shown that a major fraction of the total $\mathrm{H}_{2}$ formed $\left[g\left(\mathrm{H}_{2}\right)=0.45\right.$ molecule $/ 100 \mathrm{eV}$ at $25^{\circ} \mathrm{C}$ (for conversion into SI units, 1 molecule per $\left.\left.100 \mathrm{eV} \approx 0.10364 \mu \mathrm{mol} \mathrm{J}{ }^{-1}\right)\right]$ is due to reactions involving the precursors of the hydrated electron at short $(<1 \mathrm{ps})$ times after the initial passage of the radiation $[17,18]$. These reactions include the dissociation of excited water molecules formed by recombination of the nonhydrated electron with its parent cation $\mathrm{H}_{2} \mathrm{O}^{\bullet+}$ (geminate recombination) and the dissociative attachment of subexcitation-energy electrons (those that have kinetic energies lower than the firstelectronic excitation threshold of the medium, i.e., $\sim 7.3 \mathrm{eV}$ in liquid water) to a water molecule (DEA) [19]. Most of the rest of the formation of $\mathrm{H}_{2}$ is due to the following combination reactions between $\mathrm{e}^{-}$ and $\mathrm{H}^{\bullet}$ atoms during spur/track expansion (typically, on time scales from $\sim 1$ ps to $1 \mu \mathrm{s})[6-8,10]$ :

$$
\begin{aligned}
& \mathrm{e}^{-}{ }_{\mathrm{aq}}+\mathrm{e}^{-}{ }_{\mathrm{aq}}+2 \mathrm{H}_{2} \mathrm{O} \rightarrow \mathrm{H}_{2}+2 \mathrm{OH}^{-} \\
& \mathrm{e}^{-}{ }_{\mathrm{aq}}+\mathrm{H}^{\bullet}+\mathrm{H}_{2} \mathrm{O} \rightarrow \mathrm{H}_{2}+\mathrm{OH}^{-} \\
& \mathrm{H}^{\bullet}+\mathrm{H}^{\bullet} \rightarrow \mathrm{H}_{2}
\end{aligned}
$$

and (above $\sim 200^{\circ} \mathrm{C}$ ) $[9,15,20-22]$

$$
\mathrm{H}^{\bullet}+\mathrm{H}_{2} \mathrm{O} \rightarrow \mathrm{H}_{2}+{ }^{\bullet} \mathrm{OH}
$$

The new self-consistent radiolysis database of Elliot and Bartels [8] provides recommendations for the best values to use to model water radiolysis at temperatures up to $350^{\circ} \mathrm{C}$. Of particular significance, the rate constant for the self-reaction of $\mathrm{e}^{-}$aq $(\mathrm{R} 1)\left(k_{1}\right)$, measured in alkaline water [23-27], exhibits a "catastrophic" drop between 150 and $200^{\circ} \mathrm{C}$ and, above $250^{\circ} \mathrm{C}$, is too small to be measured reliably [8,27]. The mechanism behind this non-Arrhenius behavior above $150^{\circ} \mathrm{C}$ is not well understood, but it is generally thought to involve the formation of some transient intermediate, such as a hydrated electron dimer (or "dielectron", $\mathrm{e}_{2}{ }^{2-}$ aq) sharing the same solvent cavity, a hydride ion $\left(\mathrm{H}^{-}\right)$, or yet an "incompletely relaxed" localized electron $\left(\mathrm{e}^{-}\right.$ir $)$[23,27-29]. The applicability of this drop in $k_{1}$ above $150^{\circ} \mathrm{C}$ to neutral solution, however, has long been a subject of discussion because it could be a function of the $\mathrm{pH}$ of the solution [24]. For example, in a report published in 2002, Stuart et al. [26] wrote, "It still needs to be established whether there is a turnover of the rate constant in neutral solution". In fact, up to now, most computer modelers of the radiolysis of water at high temperatures have employed, in neutral solution, an Arrhenius extrapolation previously proposed by Elliot [24] and Stuart et al. [26]. This approach assumes that such an abrupt change in $k_{1}$ does not occur and that reaction (R1) is diffusion controlled at temperatures greater than $150^{\circ} \mathrm{C}$. This assumption was justified by the good agreement obtained between models and experiment [30-33].

However, in recent reports (and personal communication), Bartels and coworkers [8,27] emphasized that the measured temperature dependence of the (R1) reaction rate constant in alkaline solution should, in fact, be regarded as independent of $\mathrm{pH}$ and thus used in hightemperature modeling of near-neutral water radiolysis. As predicted earlier, including the drop in $k_{1}$ above $150^{\circ} \mathrm{C}$ in deterministic diffusion-kinetic modeling calculations [30,31,34] and in Monte Carlo simulations $[9,32,33]$ resulted in a sharp downward discontinuity in $g\left(\mathrm{H}_{2}\right)$, which is not observed experimentally. Figure 1 illustrates the simulation results of $g\left(\mathrm{H}_{2}\right)$ as a function of temperature as obtained recently by our group at the Université de Sherbrooke [9]. Indeed, above $\sim 150^{\circ} \mathrm{C}$ the calculations predict a decrease in $g\left(\mathrm{H}_{2}\right)$ instead of the observed increase.

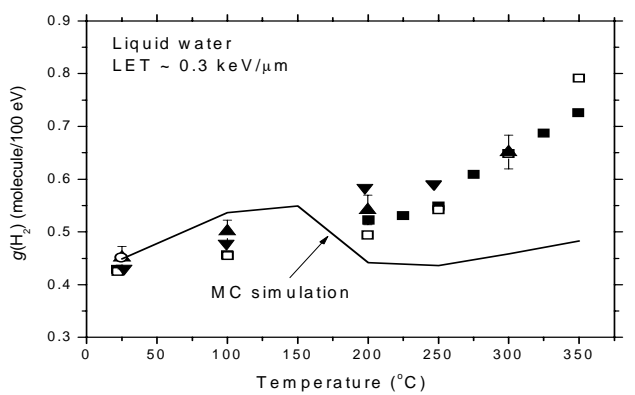

Fig. 1. Temperature dependence of the primary yield of $\mathrm{H}_{2}$ in the low-LET radiolysis of water. The solid line shows the values of $g\left(\mathrm{H}_{2}\right)$ obtained from our Monte Carlo simulations when the drop in the rate constant for the self-reaction of $\mathrm{e}^{-}$ above $150^{\circ} \mathrm{C}$ is included in the calculations [9]. The predicted $g\left(\mathrm{H}_{2}\right)$ shows a marked inflection around $150-200^{\circ} \mathrm{C}$, which is not observed experimentally. Symbols are experimental data $[6,8,10,11,12]$. 


\section{RESULTS AND DISCUSSION}

To obtain acceptable fits of our calculated values of $g\left(\mathrm{H}_{2}\right)$ to the experimental data above $150^{\circ} \mathrm{C}$, we had to adjust the temperature dependence of certain parameters involved in the early $\left(<10^{-12} \mathrm{~s}\right)$ "physicochemical stage" [35] of radiolysis, i.e., the thermalization distance of subexcitation-energy electrons $\left(r_{\text {th }}\right)$, the DEA [19,36,37], and the branching ratios of the different excited water molecule decay channels [9]. Interestingly, $g\left(\mathrm{H}_{2}\right)$ was found to be the yield most sensitive to $r_{\text {th }}$. In fact, to compensate for the decrease of $k_{1}$, a sharp decrease of $r_{\text {th }}$ above $\sim 100-150^{\circ} \mathrm{C}$ had to be included in the simulations. This decrease in $r_{\text {th }}$ was supposed to be the signature of an increase in the scattering cross sections of subexcitation electrons probably reflecting a rapid deterioration in the degree of structural order of water (due to increased breaking of hydrogen bonds) at these temperatures (these subexcitation electrons are known to be very sensitive to the structural order of the surrounding medium, owing to their non-negligible delocalized character) [9,32]. Despite the lack of clear experimental evidence for such a change in the topology of intermolecular hydrogen bonding in water above $150^{\circ} \mathrm{C}$, very good agreement was found under these conditions between simulated and experimental $g\left(\mathrm{H}_{2}\right)$, and the sharp downward discontinuity predicted at $150^{\circ} \mathrm{C}$ (Fig. 1) no longer appeared (see dotted line in Fig. 2) [9].

Recently, however, in the course of a Monte Carlo simulation study of the radiolysis of water by fast $(2 \mathrm{MeV})$ neutrons (which produce high-LET recoil protons and oxygen ions) [38], our calculations showed, somewhat unexpectedly, that $g\left(\mathrm{H}_{2}\right)$ exhibited a downward discontinuity at $\sim 150^{\circ} \mathrm{C}$ similar to that observed at low LET (Fig. 1). Closer examination revealed that this discontinuity was due, here again, to the abrupt drop in the $\left(\mathrm{e}^{-}{ }_{\text {aq }}+\mathrm{e}_{\text {aq }}^{-}\right)$reaction rate constant above $150^{\circ} \mathrm{C}$ used in the simulations. Unfortunately, the large amount of scatter in the experimental neutron radiolysis $\mathrm{H}_{2}$ yield data and also their limited availability could not allow us to determine whether or not the predicted discontinuity at $150^{\circ} \mathrm{C}$ was confirmed experimentally.

The recurrence of this discontinuity of $g\left(\mathrm{H}_{2}\right)$ at $\sim 150{ }^{\circ} \mathrm{C}$ in the case of the radiolysis of water by fast neutrons prompted us to further investigate the influence of high-LET radiation. To our knowledge, the only experimental work reporting the temperature dependence (up to $180^{\circ} \mathrm{C}$ ) of $g\left(\mathrm{H}_{2}\right)$ for the radiolysis of water at high LET is that of Elliot et al. [39] $\left(23-\mathrm{MeV}^{2} \mathrm{H}^{+}\right.$and $157-\mathrm{MeV}^{7} \mathrm{Li}^{3+}$ ions, with dose-average LETs of $\sim 11.9$ and
$62.3 \mathrm{keV} / \mu \mathrm{m}$, respectively [40]). Judging from the results of these authors (see Table 2 of [39]), there is apparently no evidence of a discontinuity in $g\left(\mathrm{H}_{2}\right)$ at $\sim 150^{\circ} \mathrm{C}$ (note that measurements were made at three temperatures only: 25,95 , and $180^{\circ} \mathrm{C}$ for both studied ions) (Fig. 2). However, as for the $2-\mathrm{MeV}$ neutron radiolysis of water and as can clearly be seen from Fig. 2, our simulations of Elliot et al.'s experiments (using our IONLYS Monte Carlo simulation code under these particular experimental conditions $[41,42])$ do reveal the presence of a pronounced discontinuity in $g\left(\mathrm{H}_{2}\right)$ at $\sim 150^{\circ} \mathrm{C}$ whose magnitude increases as the LET increases.

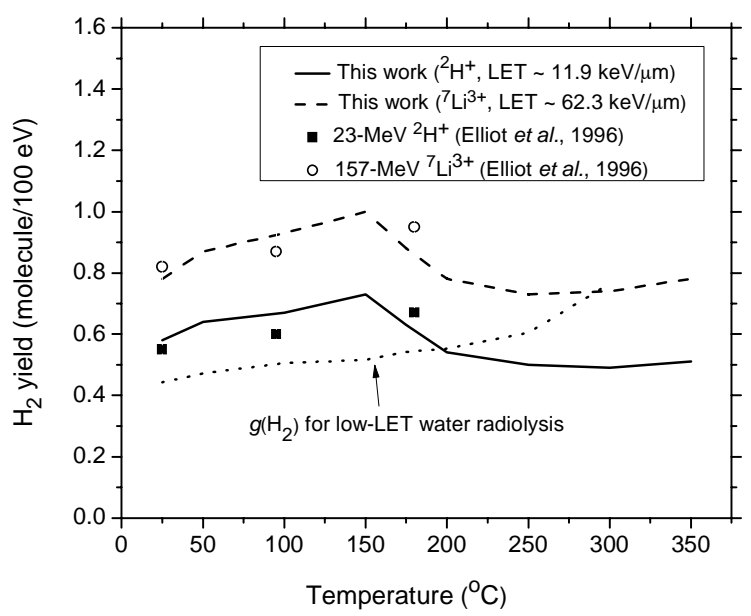

Fig. 2. Variation of the $\mathrm{H}_{2}$ yield (in molecule/100 eV) of the radiolysis of liquid water by $23-\mathrm{MeV}^{2} \mathrm{H}^{+}$and $157-\mathrm{MeV}^{7} \mathrm{Li}^{3+}$ ions as a function of temperature over the range $25-350^{\circ} \mathrm{C}$. Symbols $(0, \mathbf{m})$ represent the scavenging experimental data of Elliot et al. [39] at 25,95 , and $180^{\circ} \mathrm{C}$, as indicated in the inset. Simulated results (assuming the scavenging power varied linearly from $2 \times 10^{7} \mathrm{~s}^{-1}$ at $25^{\circ} \mathrm{C}$ to $6.5 \times 10^{7} \mathrm{~s}^{-1}$ at $95^{\circ} \mathrm{C}$ and remaining constant thereafter) are shown as solid $(23-\mathrm{MeV}$ deuterons) and dashed $\left(157-\mathrm{MeV}^{7} \mathrm{Li}^{3+}\right)$ lines. The dotted line shows our simulated primary $\mathrm{H}_{2}$ yield values for the low-LET $(\sim 0.3 \mathrm{keV} / \mu \mathrm{m})$ radiolysis of water after incorporating a discontinuity around $150^{\circ} \mathrm{C}$ in $r_{\text {th }}$, DEA, and the branching ratios of the different excited water molecule decay channels [9] [the sharp downward discontinuity predicted for $g\left(\mathrm{H}_{2}\right)$ at $150^{\circ} \mathrm{C}$ (Fig. 1) no longer appears].

At low LET, we could compensate for the decrease in $g\left(\mathrm{H}_{2}\right)$ predicted by the calculations (instead of the observed increase) by modifying the temperature dependence of $r_{\text {th }}$ (and invoking a change in the structure of water at $\sim 150^{\circ} \mathrm{C}$ ), whereas at high LET this compensation is, at first sight, no longer straightforward. Briefly, this happens because the number of self-reactions of $\mathrm{e}_{\text {aq }}^{-}$that occur in tracks greatly increases with increasing LET. This means that the influence of the abrupt drop in $k_{1}$, which is at the origin of the $g\left(\mathrm{H}_{2}\right)$ discontinuity, becomes increasingly important as the LET increases. Eventually, it will outweigh the 
compensation that was made at low LET, where the number of reactions (R1) in spurs is comparatively much less, thereby allowing the discontinuity of $g\left(\mathrm{H}_{2}\right)$ at $150^{\circ} \mathrm{C}$ to reappear. A confirmation of these results is offered by the deterministic calculations of Swiatla-Wojcik and Buxton [31] who also modeled Elliot et al.'s experiments [39] but without including the drop in $k_{1}$ at $150^{\circ} \mathrm{C}$; reasonable agreement between the model and experiment was obtained and no discontinuity in $g\left(\mathrm{H}_{2}\right)$ at $150^{\circ} \mathrm{C}$ was observed (see Fig. 1 of [31]).

Under such high-LET conditions, it seems rather difficult, if not impossible, to further modify the temperature dependence of $r_{\text {th }}$ (as we did at low LET) in order to counterbalance the effect of the drop in $k_{1}$ and obtain acceptable fits of our calculated yields to experimental data. It is, indeed, hardly conceivable that $r_{\text {th }}$ would be a function of the LET of the radiation, unless one considers the effects of local temperature increases associated with "thermal spikes" that have sometimes been proposed to occur in the tracks of heavy ions [43-45]).

\section{CONCLUSION}

Based on the above findings and in accordance with previous studies [24,26,30-33], we believe that the applicability of the sudden drop in the $\left(\mathrm{e}_{\mathrm{aq}}^{-}+\mathrm{e}_{\mathrm{aq}}^{-}\right)$reaction rate constant observed at $\sim 150^{\circ} \mathrm{C}$ in alkaline water to neutral or slightly acidic (as the $\mathrm{pH}$ of water at $150-200^{\circ} \mathrm{C}$ is about 5.7-6 [2]) solution, as proposed by Bartels and coworkers [8,27], remain uncertain and should be examined further.

Considering the importance of the self-reaction of $\mathrm{e}^{-}$aq as a main source of molecular hydrogen in high-temperature water radiolysis, further measurements of its rate constant in pure water are obviously highly desirable. These measurements, which would be extremely beneficial to the modeling community [46], would generate valuable insight for better understanding and predicting reactor coolant water chemistry in NPPs.

\section{ACKNOWLEDGMENT}

We thank Dr. A. John Elliot, Dr. Craig R. Stuart, Professor Yosuke Katsumura, Professor Mingzhang Lin, and Professor David M. Bartels for a number of helpful discussions and correspondence. Financial assistance from Atomic Energy of Canada Limited, the Natural Sciences and
Engineering Research Council of Canada, and Natural Resources Canada is gratefully acknowledged.

\section{REFERENCES}

1. W.G. Burns and P.B. Moore, Radiat. Effects 30 (1976) 233.

2. P. Cohen, Water Coolant Technology of Power Reactors, American Nuclear Society, La Grange Park, Illinois (1980).

3. R.J. Woods and A.K. Pikaev, Applied Radiation Chemistry: Radiation Processing, Wiley, New York (1994).

4. D.R. McCracken, K.T. Tsang and P.J. Laughton, Aspects of the Physics and Chemistry of Water Radiolysis by Fast Neutrons and Fast Electrons in Nuclear Reactors, Report AECL-11895, Atomic Energy of Canada Limited, Chalk River (1998).

5. H. Christensen, Fundamental Aspects of Water Coolant Radiolysis, SKI Report 2006:16, Swedish Nuclear Power Inspectorate, Stockholm, Sweden (2006).

6. J.W.T. Spinks and R.J. Woods, An Introduction to Radiation Chemistry, $3^{\text {rd }}$ ed., Wiley, New York (1990).

7. C. Ferradini and J.-P. Jay-Gerin, Can. J. Chem. 77 (1999) 1542.

8. A.J. Elliot and D.M. Bartels, The Reaction Set, Rate Constants and g-Values for the Simulation of the Radiolysis of Light Water over the Range 20 to $350^{\circ} \mathrm{C}$ Based on Information Available in 2008, Report AECL No. 153-127160-450-001, Atomic Energy of Canada Limited, Chalk River (2009).

9. S. Sanguanmith, Y. Muroya, J. Meesungnoen, M. Lin, Y. Katsumura, L. Mirsaleh Kohan, D.A. Guzonas, C.R. Stuart and J.-P. Jay-Gerin, Chem. Phys. Lett. 508 (2011) 224, and references therein.

10. A.J. Elliot, M.P. Chenier and D.C. Ouellette, J. Chem. Soc. Faraday Trans. 89 (1993) 1193.

11. D. Janik, I. Janik and D.M. Bartels, J. Phys. Chem. A 111 (2007) 7777.

12. G.R. Sunaryo, Y. Katsumura, D. Hiroishi and K. Ishigure, Radiat. Phys. Chem. 45 (1995) 131. 
13. M.C. Kent and H.E. Sims, The Yield of $\gamma-$ Radiolysis Products from Water at Temperatures up to $300^{\circ} \mathrm{C}$, Proceedings of the $6^{\text {th }}$ International Conference on Water Chemistry of Nuclear Reactor Systems (1992) 153.

14. C.C. Lin, Radiochemistry in Nuclear Power Reactors, Nuclear Science Series NAS-NS3119, National Academy Press, Washington, D.C. (1996).

15. C.D. Alcorn, J.-Cl. Brodovitch, K. Ghandi, A. Kennedy, P.W. Percival and M. Smith, Kinetics of the Reaction between $H^{\circ}$ and Superheated Water Probed with Muonium, Proceedings of the $5^{\text {th }}$ International Symposium on Supercritical-Water-Cooled Reactors (2011).

16. D.M. Bartels, J. Henshaw and H.E. Sims, Radiat. Phys. Chem. 82 (2013) 16.

17. B. Pastina, J.A. LaVerne and S.M. Pimblott, J. Phys. Chem. A 103 (1999) 5841.

18. J.A. LaVerne and S.M. Pimblott, J. Phys. Chem. A 104 (2000) 9820.

19. V. Cobut, J.-P. Jay-Gerin, Y. Frongillo and J.P. Patau, Radiat. Phys. Chem. 47 (1996) 247.

20. G.R. Sunaryo, Y. Katsumura and K. Ishigure, Radiat. Phys. Chem. 45 (1995) 703.

21. D. Swiatla-Wojcik and G.V. Buxton, Radiat. Phys. Chem. 74 (2005) 210.

22. D.M. Bartels, Radiat. Phys. Chem. 78 (2009) 191.

23. H. Christensen and K. Sehested, J. Phys. Chem. 90 (1986) 186.

24. A.J. Elliot, Rate Constants and g-Values for the Simulation of the Radiolysis of Light Water over the Range $0-300^{\circ} \mathrm{C}$, Report AECL11073, Atomic Energy of Canada Limited, Chalk River (1994).

25. A.J. Elliot, D.C. Ouellette and C.R. Stuart, The Temperature Dependence of the Rate Constants and Yields for the Simulation of the Radiolysis of Heavy Water, Report AECL-11658, Atomic Energy of Canada Limited, Chalk River (1996).

26. C.R. Stuart, D.C. Ouellette and A.J. Elliot, Pulse Radiolysis Studies of Liquid Heavy Water at Temperatures up to $250^{\circ} \mathrm{C}$, Report AECL-12107, Atomic Energy of Canada Limited, Chalk River (2002).
27. T.W. Marin, K. Takahashi, C.D. Jonah, S.D. Chemerisov and D.M. Bartels, J. Phys. Chem. A 111 (2007) 11540.

28. C. Ferradini and J.-P. Jay-Gerin, Radiat. Phys. Chem. 41 (1993) 487.

29. K.H. Schmidt and D.M. Bartels, Chem. Phys. 190 (1995) 145.

30. D. Swiatla-Wojcik and G.V. Buxton, J. Phys. Chem. 99 (1995) 11464.

31. D. Swiatla-Wojcik and G.V. Buxton, J. Chem. Soc., Faraday Trans. 94 (1998) 2135.

32. M.-A. Hervé du Penhoat, T. Goulet, Y. Frongillo, M.-J. Fraser, Ph. Bernat and J.-P. Jay-Gerin, J. Phys. Chem. A 104 (2000) 11757.

33. T. Tippayamontri, S. Sanguanmith, J. Meesungnoen, G.R. Sunaryo and J.-P. JayGerin, Recent Res. Devel. Physical Chem. 10 (2009) 143.

34. J.A. LaVerne and S.M. Pimblott, J. Phys. Chem. 97 (1993) 3291.

35. R.L. Platzman, The Vortex 23 (1962) 372.

36. T. Goulet and J.-P. Jay-Gerin, Radiat. Res. 118 (1989) 46.

37. A. Mozumder, Fundamentals of Radiation Chemistry, Academic Press, San Diego, (1999).

38. S.L. Butarbutar, S. Sanguanmith, J. Meesungnoen, G.R. Sunaryo and J.-P. JayGerin, Calculation of the Yields for the Primary Species Produced in Liquid Water by Fast Neutron Radiolysis at Temperatures between 25 and $350^{\circ} \mathrm{C}$, Proceedings of the $6^{\text {th }}$ International Symposium on Supercritical Water-Cooled Reactors (2013).

39. A.J. Elliot, M.P. Chenier, D.C. Ouellette and V.T. Koslowsky, J. Phys. Chem. 100 (1996) 9014.

40. D.E. Watt, Quantities for Dosimetry of Ionizing Radiations in Liquid Water, Taylor \& Francis, London (1996).

41. J. Meesungnoen and J.-P. Jay-Gerin, J. Phys. Chem. A 109 (2005) 6406.

42. J. Meesungnoen and J.-P. Jay-Gerin, Radiation Chemistry of Liquid Water with Heavy Ions: Monte Carlo Simulation Studies, in: Charged Particle and Photon Interactions with Matter: Recent Advances, Applications, 
and Interfaces, Y. Hatano, Y. Katsumura and A. Mozumder (Eds.), Taylor \& Francis, Boca Raton (2011) 355.

43. A. Norman, Radiat. Res. Suppl. 7 (1967) 33.

44. R.E. Apfel, Y.Y. Sun and R. Nath, Radiat. Res. 131 (1992) 124.
45. J.A. LaVerne, Radiat. Res. 153 (2000) 487.

46. P. Causey and C.R. Stuart, Test Plan for Pulse Radiolysis Studies of Water at High Temperature and Pressure, Report AECL No. 217-127160-TP-001, Atomic Energy of Canada Limited, Chalk River (2011). 